\title{
Multi-Level Gas Monitoring: A New Approach in Earthquake Research
}

\section{OPEN ACCESS}

Edited by: Giovanni Martinelli, National Institute of Geophysics and Volcanology, Section of Palermo, Italy

Reviewed by:

Fuqiong Huang,

China Earthquake Networks Center,

China

Naoji Koizumi,

University of Shiga Prefecture, Japan

${ }^{*}$ Correspondence: Heiko Woith heiko.woith@gfz-potsdam.de

Specialty section:

This article was submitted to Solid Earth Geophysics,

a section of the journal

Frontiers in Earth Science

Received: 21 July 2020 Accepted: 18 September 2020 Published: 21 October 2020

Citation:

Woith H, Daskalopoulou K, Zimmer M, Fischer T, VIček J, Trubač J, Rosberg J-E, Vylita T and Dahm T (2020) Multi-

Level Gas Monitoring: A New

Approach in Earthquake Research.

Front. Earth Sci. 8:585733.

doi: 10.3389/feart.2020.585733

\author{
Heiko Woith ${ }^{1 *}$, Kyriaki Daskalopoulou ${ }^{1}$, Martin Zimmer ${ }^{1}$, Tomáš Fischer ${ }^{2}$, Josef Vlček ${ }^{2}$, \\ Jakub Trubać ${ }^{2}$, Jan-Erik Rosberg ${ }^{3}$, Tomáš Vylita ${ }^{2}$ and Torsten Dahm ${ }^{1}$ \\ ${ }^{1}$ GFZ German Research Centre for Geosciences, Potsdam, Germany, ${ }^{2}$ Faculty of Science, Charles University, Prague, Czech \\ Republic, ${ }^{3}$ Lund University, Lund, Sweden
}

Fluid anomalies were often considered as possible precursors before earthquakes. However, fluid properties at the surface can change for a variety of reasons, including environmental changes near the surface, the response of the superficial fluid system to loads associated with the mechanical nucleation of earthquake fractures, or as a result of transients in fluid flow from the depths. A key problem is to understand the origin of the anomaly and to distinguish between different causes. We present a new approach to monitor geochemical and geophysical fluid properties along a vertical profile in a set of drillings from a depth of a few hundred meters to the surface. This setup can provide hints on the origin of temporal variations, as the migration direction and speed of properties can be measured. In addition, potential admixtures of fluids from a deep crustal or mantle origin with meteoric fluids can be better quantified. A prototype of a multi-level gas monitoring system comprising flow and pressure probes, as well as monitoring of fluid-geochemical properties and stable isotopes is being implemented in a mofette field with massive $\mathrm{CO}_{2}$ (up to 97 tons per day) degassing. The mofette is believed a gas emission site where $\mathrm{CO}_{2}$ ascends through crustal-scale conduits from as deep as the upper mantle, and may therefore provide a natural window to ongoing magmatic processes at mantle depth. Fluids from three adjacent boreholes-30, 70, and $230 \mathrm{~m}$ deep-will be continuously monitored at high sampling rates.

Keywords: mantle degassing, crustal fluids, gas monitoring, radon, swarm earthquakes, scientific drilling

\section{INTRODUCTION}

The majority of earthquake precursor studies follow a simple scheme: identify an anomaly in a timeseries (often defined as values above 2, 3, or 4 standard deviations) and then relate it one-on-one to a selected earthquake (see anomaly-earthquake compilation in Cicerone et al. (2009)). The selection of the earthquake is often arbitrary. If a magnitude-distance relation is discussed at all, the precursory strain impact at the monitoring site is often calculated according to a formula presented by Dobrovolsky et al. (1979), which according to our present-day knowledge over-estimates the size of the earthquake preparation zone significantly (Woith et al., 2018). Only few studies were truly multi-disciplinary, which is fundamental to understand the physics of earthquakes. A positive example is the design of the "Alto Tiberina Near Fault Observatory" in the northern Appenines, Italy (Chiaraluce et al., 2014). Another key problem with potentially precursory anomalies in timeseries is the correct interpretation of their origin. An anomaly physically related to the build-up of strain and stress before an earthquake might look strikingly similar to an anomaly caused by external drivers like rainfall (Woith, 2015). A typical approach to eliminate external signals from a timeseries is to use 
regressive models to predict the impact of environmental processes (like rainfall or groundwater changes) on the signal of interest. Zmazek et al. (2003) used decision trees to predict soil radon concentrations from meteorological parameters and then compared the predicted vs. the actually observed radon values. Sabbarese et al. (2020) applied a hybrid method-combining multiple linear regression, empirical mode decomposition, and support vector regression-to identify residuals and trends of radon timeseries from Campi Flegrei. A long-term increasing radon trend correlated with vertical displacement, increasing background seismicity, as well as the calculated increasing pressure and temperature of the hydrothermal system. The radon residuals correlated with tremors recorded at a fumarole. Unfortunately, such good examples of a processoriented multi-disciplinary investigation are the exception rather than the rule. Furthermore, even after the most careful and thoroughly data correction, the evidence that a trend or an anomaly is physically related to a seismo-tectonic process remains an indirect one.

A totally new perspective of a vertical array of continuous multi-parameter fluid sampling is suggested. Japanese scientists implemented a similar borehole-based concept in their most modern earthquake research observatories, which consist of three observation wells drilled to depths of 30,200, and $600 \mathrm{~m}$ (Matsumoto and Koizumi, 2013) tapping one shallow, unconfined as well as two confined aquifers. The wells are equipped with seismometers, groundwater level and temperature sensors at all three depth levels, plus tilt and strain meters usually at the deepest level. The idea is to identify strain transients in the crust, specifically to understand the groundwater response to crustal deformation related to episodic slow-slip events (Itaba et al., 2010). We adapt this idea, adding fluid geochemical composition and $\mathrm{CO}_{2}$ isotopic signatures to the online monitoring of geophysical parameters. This will help to distinguish the different origins of anomalies and to separate down- and upward migrating transients in the fluid system analog to observations already made by Hatuda (1953). Hatuda measured the radon concentration of soil air from 0.6, 1, and $2 \mathrm{~m}$ depth once a day for more than 2 years and noted about an earthquake-related anomaly "the deeper the sampling site was, the greater proportionately was the increase in concentration, an instance opposite to the case where meteorological influences are at work".

\section{MULTI-LEVEL GAS MONITORING}

\section{Strategy}

The strategy is to monitor the gas composition and its isotopic signature continuously at different depth levels. If the fluid composition changes at depth-e.g., due to the admixture of crustal components to an otherwise steady mantle degassing during swarm earthquakes as proposed by Weise et al. (2001) for our investigation area-it will take a certain amount of time until the changes can be detected at the Earth's surface. The time delay depends on the velocity of the rising fluids. In a comprehensive review, Etiope and Martinelli (2002) compared the effectiveness of gas migration processes in the geosphere. Neither diffusion (with average velocities below $10^{-2} \mathrm{~m} /$ day), nor groundwater advection can explain fast vertical gas migration. Instead, in permeable rocks with fracture apertures within the range between 0.01 and $10 \mathrm{~mm}$, advective migration of gas with velocities between 1 and $1,000 \mathrm{~m}$ /day is feasible. At Mammoth Mountains, Sorey et al. (1998) suggested velocities of the order of $10-40 \mathrm{~m} /$ day for the transport of $\mathrm{CO}_{2} /$ helium from a depth of $2-4 \mathrm{~km}$. Slightly higher values were obtained by Lewicki et al. (2014), who concluded that $\mathrm{CO}_{2}$ migrated from a depth of about $20 \mathrm{~km}$ to the surface at Mammoth Mountains in less than a year, corresponding to a velocity of $50+\mathrm{m} /$ day. Six months before the eruption of Usu volcano the $\mathrm{CO}_{2}$ flux increased significantly in the summit caldera (Hernandez et al., 2001). Seismic data indicated magma $4 \mathrm{~km}$ below the summit, which yields a migration velocity of about $20 \mathrm{~m} /$ day. $\mathrm{A} \mathrm{CO}_{2}$ increase was also observed $50 \mathrm{~d}$ before the El Hierro eruption (Peréz et al., 2012), indicating a fluid velocity of the order of $100 \mathrm{~m} /$ day. For the Cheb Basin, gas migration velocities are rather uncertain. While the estimates of Weise et al. (2001) and Bräuer et al. (2003) range between 50 and $400 \mathrm{~m} /$ day for fractured basement rocks (granites, phyllites), the fast and long-term postseismic gas flow increase in the Hartoušov mofette (Fischer et al., 2017) points to velocities more than $2 \mathrm{~km} /$ day. If we assume similar fluid transport velocities for the subsurface, the delay time between the deepest well $(230 \mathrm{~m})$ and the surface would be somewhere in the range between several days and few hours. Thus, with a measurement interval of fractions of an hour we should be able to detect transients coming from below. The same logic applies to changes coming from above, i.e. changes induced by rain, snowmelt, and water level changes in shallow aquifers.

\section{Technical Setup}

Hartoušov mofette field is located in the Cheb Basin (West Bohemia) and is known for intense mantle- $\mathrm{CO}_{2}$ degassing and nearby recurring earthquake swarms (Figure 1A) (Fischer et al., 2014; Bräuer et al., 2018). Estimated daily $\mathrm{CO}_{2}$ flux of up to $97 \mathrm{t}$ over an area of about $350,000 \mathrm{~m}^{2}$ (Nickschick et al., 2015) and long-term monitoring of gas flow in shallow borehole F1 made it a key site to study fluid-earthquake-interactions in the frame of ICDP Project: "Drilling the Eger Rift: Magmatic fluids driving the earthquake swarms and the deep biosphere" (Dahm et al., 2013). Three adjacent boreholes have been drilled about $90 \mathrm{~m} \mathrm{NW}$ of a natural mofette (Figure 1B): F1, F2, and F3 to a depth of 28.2, 108.5 , and $239.3 \mathrm{~m}$, respectively. F1 was drilled in 2007 and taps a $\mathrm{CO}_{2}$-rich shallow aquifer; a plastic casing of $115 \mathrm{~mm}$ is perforated between 20 and $28 \mathrm{~m}$. Gas flow measurements started in 2009 (Fischer et al., 2020). F2 was drilled in 2016 to study geo-bio interactions in extreme environments (Bussert et al., 2017). At a depth of $78.5 \mathrm{~m}$ a $\mathrm{CO}_{2}$ blowout occurred. Following a pumping test, which produced a mixture of gas and mineralized water, the well was closed and the wellhead pressure of about $500 \mathrm{kPa}$ remained stable, except for two events of unknown origin in July 2016 when the pressure dropped to $50 \mathrm{kPa}$ within hours before returning to the pre-event level after some days. In September 2019, a set of sensors was installed in F2 as shown 


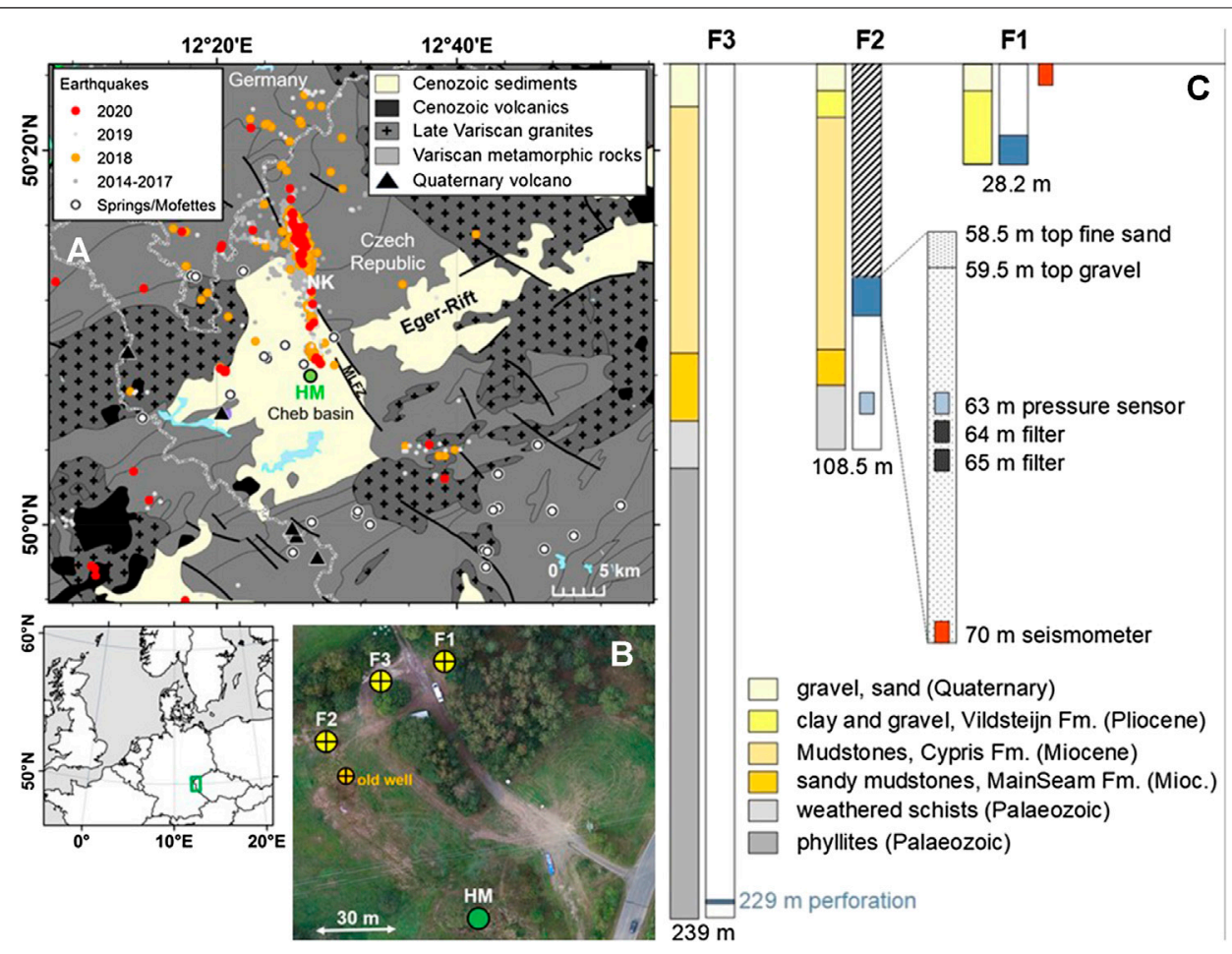

FIGURE 1 | Technical set-up of the multi-level gas monitoring system. (A) Geological map [simplified from the "Geological Map of Germany 1:1,000,000 (GK1000)", $\mathrm{BGR}$ ] showing the position of the Hartoušov mofette $(\mathrm{HM})$ in the Eger-Rift. White circles mark mofettes and springs with $\mathrm{CO}_{2}>1 \mathrm{~g} / \mathrm{L}$. Orange and red dots depict seismic activity during 2018 and 2020, respectively. NK - Nový Kostel focal zone (B) Bird's view of the boreholes and the natural Hartoušov mofette, (C) simplified lithological section of boreholes F1, F2, and F3. Sensor configuration of F2. Perforated sections of the wells are marked in blue.

in Figure 1C. Within 3 years after the drilling, the lowermost part of the borehole obviously filled up with sediments. Thus, a borehole seismometer (ASIR AFF1.005) was installed at the deepest possible position at $70 \mathrm{~m}$. At 65 and $64 \mathrm{~m}$ two stainless-steel filters were fixed and connected to capillary tubes of $4 \mathrm{~mm}$ inner diameter. Finally, a pressure sensor (KELLER PAA36-XW) was placed at a depth of $63 \mathrm{~m}$ before the instrumented borehole section was filled with gravel and $1 \mathrm{~m}$ of fine sand on top. The uppermost part of the well was filled with cement. In August 2019, F3 was drilled half-way between F1 and F2 and various gas-bearing horizons have been encountered between $110 \mathrm{~m}$ and the final depth of $238 \mathrm{~m}$.

Instrumentation for the on-site gas analysis is installed at F1 and comprises a QMS (Omnistar Quadrupole Mass Spectrometer by Pfeiffer Vacuum), an infrared gas analyser (DeltaRay by Thermo-Fischer), and three radon detectors (by GFZ)-one for each well. QMS measures the gas composition, i.e. $\mathrm{H}_{2}, \mathrm{He}$, $\mathrm{CO}_{2}, \mathrm{Ar}, \mathrm{N}_{2}, \mathrm{O}_{2}$, and $\mathrm{CH}_{4}$, whereas the DeltaRay measures $\mathrm{CO}_{2}$, $\delta^{13} \mathrm{C}$, and $\delta^{18} \mathrm{O}$. A multi-valve is connected to $\mathrm{F} 1, \mathrm{~F} 2$, and $\mathrm{F} 3$ via capillary tubes and thus it is possible to measure all three wells with one set of instruments one after the other in a cycling mode. For details of the applied techniques the reader is referred to Zimmer et al. (2011 and 2018). Given $\mathrm{CO}_{2}$ concentrations above 99.5\%, small changes in the $\mathrm{CO}_{2}$ concentration will be difficult, if not impossible, to detect. Hence, monitoring and recording the temporal variations of the other gas components found in minor abundances is crucial. Discrete fluid sampling complements the online monitoring program including noble gases, specifically the ${ }^{3} \mathrm{He} /{ }^{4} \mathrm{He}$ and ${ }^{4} \mathrm{He} /{ }^{20} \mathrm{Ne}$ ratios.

Additional to the gas monitoring equipment, the following instruments are installed:

- A weather station (Vaisala WXT536) records meteorological standard parameters.

- A broadband seismometer (Trillium Compact $120^{\prime \prime}$ ) is installed outside of F1.

- At F1 the gas flow is recorded with a drum gas counter (RITTER), water temperature and water level/pressure is measured at three different depth levels. The gas pressure is measured in the wellhead. Details are given in Fischer et al. (2020).

- At F2 fluid pressure is measured at a depth of 92 and $63 \mathrm{~m}$. A borehole seismometer was installed at $70 \mathrm{~m}$.

- F3 instrumentation will be completed similar to F2, if technically feasible.

\section{First Results}

We present measurements obtained during the drilling phase of the deepest borehole F3. The most important aim of the F3 drilling was to find additional $\mathrm{CO}_{2}$-bearing strata below $100 \mathrm{~m}$. Drill-site selection was difficult despite various geophysical presite surveys. From the analysis of noise tremors using matched 


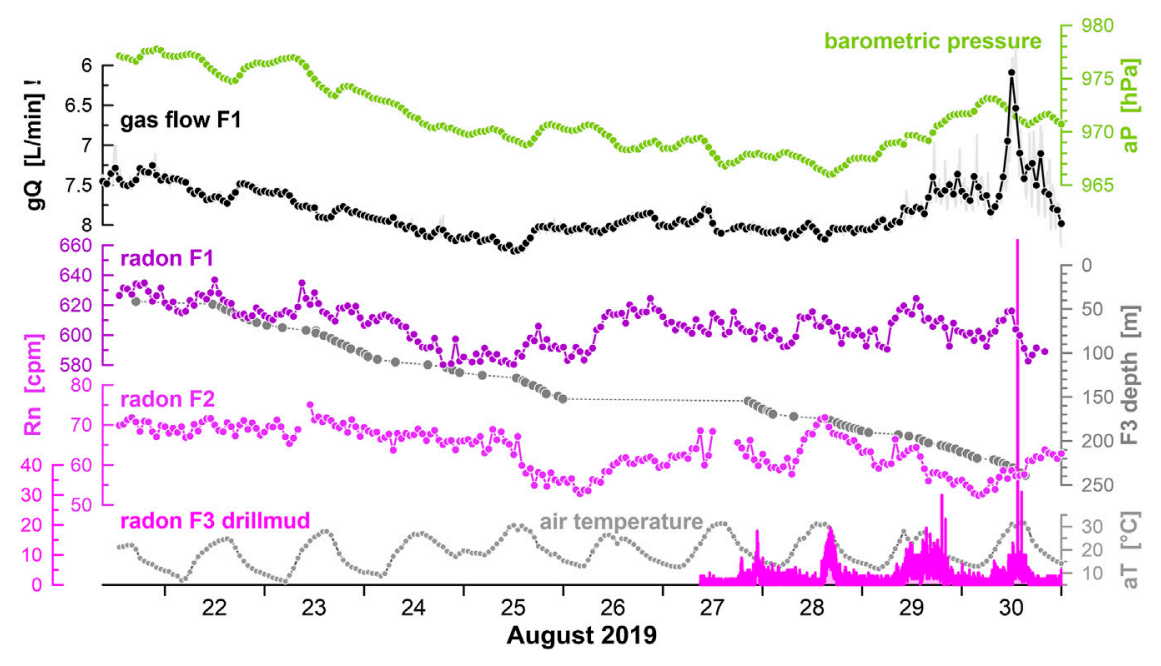

FIGURE 2 | Hourly averages of barometric pressure, gas flow rate of F1, radon concentration of F1 and F2 as well as in the drillmud of F3 (1-min raw data), and air temperature during the drilling phase. Note the inverted $Y$-axis of the gas flow. Drill depths estimated from core-on-deck times.

field processing techniques Umlauft and Korn (2019) postulated a northward dipping fluid channel down to a depth of $100 \mathrm{~m}$. The center of the noise anomaly at a depth of $100 \mathrm{~m}$ was located slightly east of the old well (see Figure 1B). Extrapolating this trend to greater depth indicated that the fluid channel is hit at a depth of about $200 \mathrm{~m}$ at the location of F3 (see Figure 1B). Interestingly, the surface $\mathrm{CO}_{2}$ flux measurements by Nickschick et al. (2015) observed only moderate values at the F3 borehole position. Drilling operations started in August 2019. At first, two anchor pipes were cemented down to a depth of 15 and $40 \mathrm{~m}$. Between 21 and August 30, 2019 drilling continued until a final depth of $239.3 \mathrm{~m}$ was reached. During all drilling operations, a blowout-preventer was used. Due to a heavy drillmud $(1.15 \mathrm{~g} /$ $\mathrm{cm}^{3}$ ) no gas eruptions were encountered. Cores of $83 \mathrm{~mm}$ were obtained; sub-samples for microbiological studies were deepfrozen on site. The borehole was completely cased with steel rods (ID about $78 \mathrm{~mm}$ ) and cemented.

A further challenge was the selection of the perforation depth. Significant degassing of the fresh cores started at a depth of $110 \mathrm{~m}$ and was observed until the final depth with varying intensities. To identify the most promising $\mathrm{CO}_{2}$-horizon a combination of different methods was applied: visual inspection of core material, fluid sampling from cores, online gas monitoring of the drillmud, and finally borehole logging of the open hole after the drilling was completed. Pyrite occurred prominently at 175 and $230 \mathrm{~m}$ depth, preferentially on interfaces (divisional surface) within the mica schists and might be indicative for the circulation of $\mathrm{CO}_{2}$-rich fluids under reducing conditions (personal communication Robert Bussert, 2020). The core section 226-234 m was heavily fractured. Another hint for permeable, fluid-filled fractures was obtained from the online radon measurements of the drillmud, which showed a clear spike at a depth of about $230 \mathrm{~m}$ (Figure 2). The perforation of the steel casing was performed on January 15, 2020 at a depth of $229 \mathrm{~m}$. On February 6, 2020 the water level of F3 was lowered to $15 \mathrm{~m}$ below the surface. Thereafter the wellhead was closed and a pressure built-up of $60 \mathrm{kPa}$ was observed within the next $3 \mathrm{~h}$. The test was repeated on March 10, 2020. Lowering the water level to $80 \mathrm{~m}$ resulted in a pressure increase of $120 \mathrm{kPa}$ within $6 \mathrm{~h}$.

An important question immediately arises: Are the boreholes hydraulically connected? Online monitoring revealed i) a fluid pressure transient of $10 \mathrm{kPa}$ in F2 between 24 and August 25, 2019. The anomaly started when F3 reached a depth of about $110 \mathrm{~m}$, i.e. when the first significant degassing of the cores could be observed, ii) a drop in the gas flow at F1 on 30 August while the radon concentration in the drillmud showed its maximum (Figure 2). The latter event coincides with a conductivity increase and a decreased redox potential at the natural mofette located about $90 \mathrm{~m}$ SE of the drillsite, both indicating the admixture of a mineralized deep fluid component to the low-conductivity shallow water typically present at the Hartoušov mofette. The raw data presented in Figure 2 indicate similarities between the F1 gas flow and the radon concentrations in F1 and F2, which are likely due temperature and barometric pressure effects. Barometric pressure and gas flow at F1 are clearly anti-correlated. For an indepth discussion about the environmental effects on the gas flow the reader may refer to Fischer et al. (2020). Radon in the drillmud of F3 seems to be unrelated to barometric pressure and air temperature variations (radon spikes occur at 00:00, 18:00, 21: 00 , and 15:00 local time). There was no rainfall except two small events around noon on 26 and 29 August with 5 and $2 \mathrm{~mm}$ of rain, respectively. Seismic activity could be ruled out to explain the described transients. During the drilling operation maximum coseismic strains remained below one nanostrain, i.e. smaller than the Earth's tidal strain. That may change in future, because earthquakes migrated further to the south toward our monitoring site in recent years. The southernmost cluster of the Nový Kostel (NK) seismic zone occurs only 2-3 km NNE from the Hartoušov mofette and demonstrates increasing seismicity rate. Its activity culminated during the 2018 swarm by a short sequence reaching the magnitude of 3.1 in a cluster located about $3 \mathrm{~km}$ north 
of Hartoušov mofette (see orange dots in Figure 1). This may, along with the ongoing southward migration of hypocenters in 2020 (see red dots in Figure 1), generate strains capable of interfering the gas paths from the depth to the surface.

\section{DISCUSSION AND OUTLOOK}

A prototype of a multi-level gas monitoring system installed at three wells tapping $\mathrm{CO}_{2}$-horizons at 20, 65, and $229 \mathrm{~m}$ has been set-up in a mofette site. Seismometers and a weather station were installed on-site in order to quantify the impact of earthquakes as well as environmental effects on the fluid regime. Continuous radon measurements while drilling revealed a promising $\mathrm{CO}_{2}$ horizion, which was later chosen for the perforation of the steel casing. Further hydraulic tests at F3 are needed to confirm whether the perforation was successful. Ultimately, a borehole seismometer will be installed at the bottom of F3 as well as a capillary tube to collect "fresh" gases from the $\mathrm{CO}_{2}$-horizon at depth. It is very important to collect the gas directly at the point where the fluids enter the borehole. Otherwise the measurements might be affected by external processes like "barometric pumping" inside the open well as described by Zafrir et al. (2016).

It is fair to note, that the complex geological underground at the Hartoušov mofette makes a proper measurement of a fluid gradient and thus a correct velocity estimate demanding. Fluid flow is assumed to preferentially occur along fractures or channels which may change in time. Miller and Nur (2000) noted that the local permeability can change instantaneously from extremely low to extremely high values. For the Hartoušov mofette field, evidences that the degassing pattern is highly dynamic in space and time were already provided by Nickschick et al. (2015), who found variations between 1 and $100 \mathrm{~g} / \mathrm{m}^{2}$ per day. Flores Estrella et al. (2016) revealed from repeated seismic array measurements changes in the flow pattern from 1 day to the next. What causes short-term pressure transients (in the order of days) observed in mofettes? Weinlich (2014) observed sharp $\mathrm{CO}_{2}$ peaks in the Soos mofette-located less than $5 \mathrm{~km}$ WNW of Hartoušov-lasting less than $24 \mathrm{~h}$. Either sudden fault permeability changes or pressure pulses induced by fault movements were discussed based on the short duration of the anomalies, but not finally proven. The seismic sequence of October 2008 and May 2014 triggered a fast and steady increase of $\mathrm{CO}_{2}$ flow monitored at the F1 borehole in the Hartoušov mofette field (Fischer et al., 2017). Contrary, the same mofette did not respond either to the 2011 earthquake swarm or to the most recent swarms of 2017 and 2018. Is a threshold value needed to activate the postulated faultvalve mechanism? More data and experiments are needed to develop, constrain, and calibrate a hydro-mechanical model for the mofette system. Once our novel monitoring system is fully operational, fluid transients can be observed in great detail. We expect new insights into the physical processes that control the complex interplay between earthquakes, deep degassing, and permeability variations along the path to the surface.

\section{DATA AVAILABILITY STATEMENT}

The data analyzed in this study is subject to the following licenses/ restrictions: Data related to the drilling operations are stored in the drilling information system (DIS) of the ICDP. After a short embargo time, the data will be made available at http:// dataservices.gfz-potsdam.de/portal/. Requests to access these datasets should be directed to Heiko Woith, heiko.woith@gfzpotsdam.de.

\section{AUTHOR CONTRIBUTIONS}

HW, TF, and TD developed the conception and design of the study; JER was responsible for the scientific drilling of F3. TV provided valuable knowledge about the hydrogeology of the Cheb Basin and supervised the drilling process. KD and MZ setup the online measurements of the gas composition with a mass spectrometer, JV is responsible for gas flow and water level measurement, JT set-up the instrument for the onsite monitoring of the stable isotopes $\delta^{13} \mathrm{C}$ and $\delta^{18} \mathrm{O}$, while HW developed radon detectors used in this study; HW wrote the first draft of the manuscript. All authors contributed to manuscript revision, read and approved the submitted version.

\section{FUNDING}

Drilling operations have been funded by ICDP (International Continental Scientific Drilling Program) in the frame of the project "Drilling the Eger Rift: Magmatic fluids driving the earthquake swarms and the deep biosphere" and were partially supported also by GFZ. The infrared gas analyzer was obtained in the frame of the CzechGeo/EPOS-Sci infrastructure (CZ.02.1.01/0.0/0.0/16_013/0001800) co-funded by the EU Operational Program Research, Development and Education. This work is a part of MoRe- "Mofette Research"-project which was funded by the Deutsche Forschungsgemeinschaft (DFG, German Research Foundation)-419880416.

\section{ACKNOWLEDGMENTS}

We are grateful for constructive comments by two reviewers which helped to improve our manuscript. For technical guidance before and during the drilling we are grateful to Ulrich Harms, Thomas Wiersberg, Santiago Aldaz, and Jochem Kück of the operational support group of ICDP. Last, but not least we thank the international team of drillers from Protek Norr AB and PRUY KG, with special thanks to Danilo Pruy (Saxonia), Johan Kullenberg from Lund University/Riksriggen (Sweden), and Friðfinnur K Danielsson (Iceland). 


\section{REFERENCES}

Bräuer, K., Kämpf, H., Niedermann, S., and Strauch, G. (2018). Monitoring of helium and carbon isotopes in the western Eger Rift area (Czech Republic): relationships with the 2014 seismic activity and indications for recent (20002016) magmatic unrest. Chem. Geol. 482, 131-145. doi:10.1016/j.chemgeo. 2018.02.017.

Bräuer, K., Kämpf, H., Strauch, G., and Weise, S. M. (2003). Isotopic evidence $\left({ }^{3} \mathrm{He} /\right.$ ${ }^{4} \mathrm{He},{ }^{13} \mathrm{C}_{\mathrm{CO} 2}$ ) of fluid-triggered intraplate seismicity. J. Geophys. Res., B 108 (B2), 2070. doi:10.1029/2002JB002077.

Bussert, R., Kämpf, H., Flechsig, C., Hesse, K., Nickschick, T., Liu, Q., et al. (2017). Drilling into an active mofette: pilot-hole study of the impact of $\mathrm{CO}_{2}$-rich mantle-derived fluids on the geo-bio interaction in the western Eger Rift (Czech Republic). Sci. Dril. 23, 13-27. doi:10.5194/sd-23-13-2017.

Chiaraluce, L., Amato, A., Carannante, S., Castelli, V., Cattaneo, M., Cocco, M., et al. (2014). The Alto Tiberina near fault observatory (northern Apennines, Italy). Ann. Geophys. 57 (3), 16. doi:10.4401/ag-6426.

Cicerone, R. D., Ebel, J. E., and Britton, J. (2009). A systematic compilation of earthquake precursors. Tectonophysics 476 (3-4), 371-396. doi:10.1016/j.tecto. 2009.06.008.

Dahm, T., Hrubcová, P., Fischer, T., Horálek, J., Korn, M., Buske, S., et al. (2013). Eger Rift ICDP: an observatory for study of non-volcanic, mid-crustal earthquake swarms and accompanying phenomena. Sci. Dril. 16, 93-99. doi:10.5194/sd-16-93-2013.

Dobrovolsky, I. P., Zubkov, S. I., and Miachkin, V. I. (1979). Estimation of the size of earthquake preparation zones. Pure Appl. Geophys. 117 (5), 1025-1044. doi:10.1007/BF00876083.

Etiope, G., and Martinelli, G. (2002). Migration of carrier and trace gases in the geosphere: an overview. Phys. Earth Planet. Inter. 129 (3-4), 185-204. doi:10. 1016/S0031-9201(01)00292-8.

Fischer, T., Horálek, J., Hrubcová, P., Vavryčuk, V., Bräuer, K., and Kämpf, H. (2014). Intra-continental earthquake swarms in West-Bohemia and Vogtland: a review. Tectonophysics 611, 1-27. doi:10.1016/j.tecto.2013.11.001.

Fischer, T., Matyska, C., and Heinicke, J. (2017). Earthquake-enhanced permeability-evidence from carbon dioxide release following the M L 3.5 earthquake in West Bohemia. Earth Planet Sci. Lett. 460, 60-67. doi:10.1016/j. epsl.2016.12.001

Fischer, T., Vlček, J., and Lanzendörfer, M. (2020). Monitoring crustal $\mathrm{CO}_{2}$ flow: methods and their applications to the mofettes in West Bohemia. Solid Earth. 11, 983-998. doi:10.5194/se-11-983-2020.

Flores Estrella, H., Umlauft, J., Schmidt, A., and Korn, M. (2016). Locating mofettes using seismic noise records from small dense arrays and matched field processing analysis in the NW Bohemia/Vogtland Region, Czech Republic. Near Surf. Geophys. 14 (4), 327-335. doi:10.3997/1873-0604. 2016024.

Hatuda, Z. (1953). Radon content and its change in soil air near the ground surface. Mem. College Sci., Univ. Kyoto, Series B 20 (4), 285-306.

Hernandez, P. A., Notsu, K., Salazar, J. M., Mori, T., Natale, G., Okada, H., et al. (2001). Carbon dioxide degassing by advective flow from Usu Volcano, Japan. Science 292 (5514), 83-86. doi:10.1126/science.1058450

Itaba, S., Koizumi, N., Matsumoto, N., and Ohtani, R. (2010). Continuous observation of groundwater and crustal deformation for forecasting Tonankai and Nankai earthquakes in Japan. Pure Appl. Geophys. 167 (8-9), 1105-1114. doi:10.1007/s00024-010-0095-z.

Lewicki, J. L., Hilley, G. E., Shelly, D. R., King, J. C., McGeehin, J. P., Mangan, M., et al. (2014). Crustal migration of CO2-rich magmatic fluids recorded by treering radiocarbon and seismicity at Mammoth Mountain, CA, USA. Earth Planet Sci. Lett. 390, 52-58. doi:10.1016/j.epsl.2013.12.035.

Matsumoto, N., and Koizumi, N. (2013). Recent hydrological and geochemical research for earthquake prediction in Japan. Nat. Hazards. 69 (2), 1247-1260. doi:10.1007/s11069-011-9980-8.
Miller, S. A., and Nur, A. (2000). Permeability as a toggle switch in fluid-controlled crustal processes. Earth Planet Sci. Lett. 183 (1-2), 133-146. doi:10.1016/s0012$821 \mathrm{x}(00) 00263-6$

Nickschick, T., Kämpf, H., Flechsig, C., Mrlina, J., and Heinicke, J. (2015). $\mathrm{CO}_{2}$ degassing in the Hartoušov mofette area, western Eger Rift, imaged by $\mathrm{CO}_{2}$ mapping and geoelectrical and gravity surveys. Int. J. Earth Sci. 104 (8), 2107-2129. doi:10.1007/s00531-014-1140-4.

Pérez, N. M., Padilla, G. D., Padrón, E., Hernández, P. A., Melián, G. V., Barrancos, J., et al. (2012). Precursory diffuse $\mathrm{CO}_{2}$ and $\mathrm{H}_{2} \mathrm{~S}$ emission signatures of the 2011-2012 El Hierro submarine eruption, Canary Islands. Geophys. Res. Lett. 39 (16), L16311. doi:10.1029/2012GL052410.

Sabbarese, C., Ambrosino, F., Chiodini, G., Giudicepietro, F., Macedonio, G., Caliro, S., et al. (2020). Continuous radon monitoring during seven years of volcanic unrest at Campi Flegrei caldera (Italy). Sci. Rep. 10 (1), 9551. doi:10. 1038/s41598-020-66590-w.

Sorey, M. L., Evans, W. C., Kennedy, B. M., Farrar, C. D., Hainsworth, L. J., and Hausback, B. (1998). Carbon dioxide and helium emissions from a reservoir of magmatic gas beneath Mammoth Mountain, California. J. Geophys. Res. 103 (B7), 15303-15323. doi:10.1029/98jb01389

Umlauft, J., and Korn, M. (2019). 3-D fluid channel location from noise tremors using matched field processing. Geophys. J. Int. 219 (3), 1550-1561. doi:10. 1093/gii/ggz385.

Weinlich, F. H. (2014). Carbon dioxide controlled earthquake distribution pattern in the NW Bohemian swarm earthquake region, western Eger Rift, Czech Republic - gas migration in the crystalline basement. Geofluids 14 (2), 143-159. doi:10.1111/gfl.12058.

Weise, S. M., Bräuer, K., Kämpf, H., Strauch, G., and Koch, U. (2001). Transport of mantle volatiles through the crust traced by seismically released fluids: a natural experiment in the earthquake swarm area Vogtland/NW Bohemia, Central Europe. Tectonophysics 336 (1-4), 137-150. doi:10.1016/s0040-1951(01)00098-1

Woith, H. (2015). Radon earthquake precursor: a short review. Eur. Phys. J. Spec. Top. 224 (4), 611-627. doi:10.1140/epjst/e2015-02395-9.

Woith, H., Petersen, G. M., Hainzl, S., and Dahm, T. (2018). Review: can animals predict earthquakes? Bull. Seismol. Soc. Am. 108 (3A), 1031-1045. doi:10.1785/ 0120170313

Zafrir, H., Ben Horin, Y., Malik, U., Chemo, C., and Zalevsky, Z. (2016). Novel determination of radon-222 velocity in deep subsurface rocks and the feasibility to using radon as an earthquake precursor. J. Geophys. Res. Solid Earth. 121 (9), 6346-6364. doi:10.1002/2016jb013033.

Zimmer, M., Erzinger, J., and Kujawa, C., and CO2SINK-Group (2011). The gas membrane sensor (GMS): a new method for gas measurements in deep boreholes applied at the CO2SINK site. Int. J. Greenhouse Gas Control. 5 (4), 995-1001. doi:10.1016/j.jiggc.2010.11.007.

Zimmer, M., Szizybalski, A., Norden, B., Vieth-Hillebrand, A., and Liebscher, A., and the Ketzin Group (2018). Monitoring of the gas composition and stable carbon isotopes during side track drilling in Ktzi 203 at the Ketzin $\mathrm{CO}_{2}$ storage pilot site, Germany. Adv. Geosci. 45, 7-11. doi:10.5194/adgeo-45-7-2018.

Zmazek, B., Todorovski, L., Džeroski, S., Vaupotič, J., and Kobal, I. (2003). Application of decision trees to the analysis of soil radon data for earthquake prediction. Appl. Radiat. Isot. 58 (6), 697-706. doi:10.1016/s0969-8043(03)00094-0

Conflict of Interest: The authors declare that the research was conducted in the absence of any commercial or financial relationships that could be construed as a potential conflict of interest.

Copyright $\odot 2020$ Woith, Daskalopoulou, Zimmer, Fischer, Vlček, Trubač, Rosberg, Vylita and Dahm. This is an open-access article distributed under the terms of the Creative Commons Attribution License (CC BY). The use, distribution or reproduction in other forums is permitted, provided the original author $(s)$ and the copyright owner(s) are credited and that the original publication in this journal is cited, in accordance with accepted academic practice. No use, distribution or reproduction is permitted which does not comply with these terms. 